\title{
Mechanism and evolution of the DNA repair enzyme MutY
}

Martin P. Horvath ${ }^{1,}$, Evan P. Drage ${ }^{1}$, Emily Dart ${ }^{1}$, Peyton Russelburg ${ }^{1}$, Valerie L. O’Shea ${ }^{2,3}$, Ryan D. Woods ${ }^{3}$, Aurea $^{2}$ $\mathrm{Chu}^{3}$, Sheng $\mathrm{Cao}^{3}$, Jody L. Richards ${ }^{3}$, Sheila S. David ${ }^{3}$

${ }^{1}$ Department of Biology, University of Utah, Salt Lake City, UT 84112, USA

${ }^{2}$ Department of Chemistry, University of Utah, Salt Lake City, UT 84112, USA

${ }^{3}$ Department of Chemistry, University of California, Davis, Davis CA 95616, USA

Key words: enzyme mechanism, protein evolution, protein-DNA complex, x-ray crystallography, cancer

The chemical structure of DNA must be continually repaired. MutY removes adenine to initiate repair at OG:A lesions in DNA. It is found in all three kingdoms of life, underscoring its importance for genome integrity. Clinical variants of human MutY (MUTYH) are associated with colon cancers. The structure of MutY from Geobacillus stearothermophilus in complex with DNA containing a transition state mimic (pdb id $5 d p k$ ) revealed new mechanistic insights, including a catalytic role for a tyrosine residue (Tyr126) and retention of stereochemistry at C1', and further suggested that a DNA-enzyme covalent intermediate intercepts the oxacarbenium ion transition state (TS). The azaribose $(1 \mathrm{~N})$ likely mimics a late TS encountered after adenine departure from the active site. To examine interactions of active site residues with the predicted early TS, we have now refined a structure of MutY in complex with DNA containing an adenine-like group at N1'. Structures for the Tyr126 $\rightarrow$ Ser and Tyr126 $\rightarrow$ Phe substitution variants reveal consequences of removing this active site residue. To explore constraints on MutY over evolution, we are beginning to characterize homologs from Archaea and from environmental samples obtained at the Lost City, an alkaline hydrothermal field found in the Atlantic ocean.

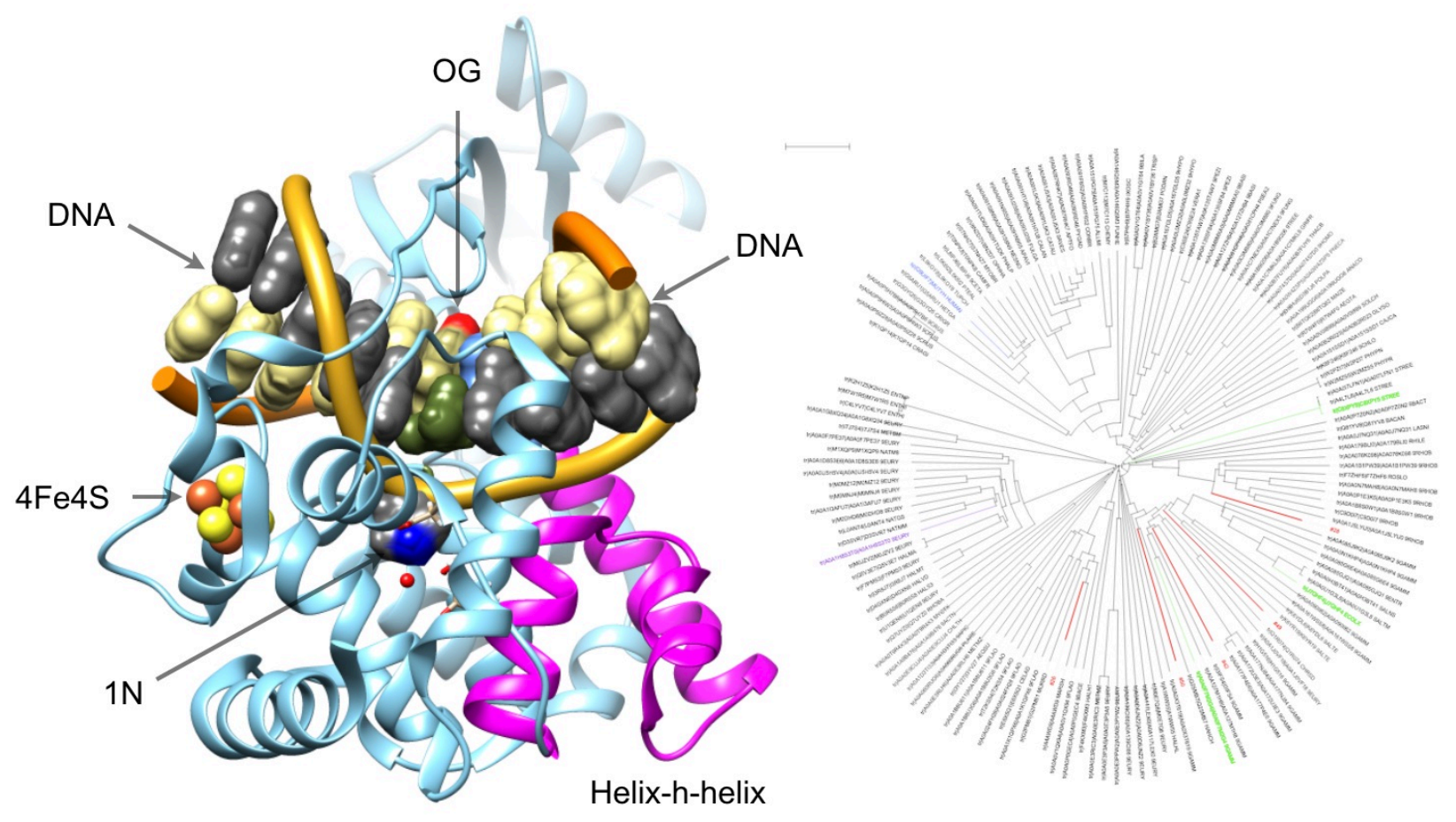

